\title{
Ritonavir: A Powerful Boosting Agent for Overcoming Drug Resistance in Cancer Chemotherapy
}

Ramya Krishna Vadlapatla ${ }^{1,2}$, Dhananjay Pal ${ }^{1 *}$, Aswani Dutt Vadlapudi',2 and Ashim K Mitra ${ }^{1}$

${ }^{1}$ Division of Pharmaceutical Sciences, School of Pharmacy, University of Missouri-Kansas City, 2464 Charlotte Street, Kansas City, MO 64108, USA ${ }^{2}$ Manufacturing Technical Services, Mylan Pharmaceuticals Inc, 781 Chestnut Ridge Road, Morgantown, WV 26505, USA

\begin{abstract}
Purpose: A major impediment to successful drug therapy is the development of multidrug resistance (MDR). Drug resistance in HIV patients is also well known. The introduction of highly active antiretroviral therapy (HAART) has substantially reduced HIV resistance and fatalities. It appears that ritonavir along with another protease inhibitor regulates both drug efflux and metabolism to overcome resistance in HIV-infected patients. Therefore, we have examined a similar strategy of combining ritonavir with anticancer drugs to modulate drug efflux, metabolism and allow sufficient drug entry into tumor cells.
\end{abstract}

Methods: Cells were treated for 72 hours with anticancer drugs alone and in the presence of ritonavir. Quantitative gene expression studies, immunoblot analysis, radioactive uptake studies and Vivid ${ }^{\mathrm{TM}}$ fluorescent assay were performed on human colon adenocarcinoma cells (LS180) cells. Cell proliferation, migration and apoptosis assays were performed on human breast adenocarcinoma (T47D) cells and prostate cancer (PC-3) cells.

Results: The overexpression of efflux transporters and metabolizing enzymes was diminished when cells were co-treated with ritonavir. $\left.{ }^{3} \mathrm{H}\right]$ Lopinavir uptake and $\mathrm{VIVID}{ }^{\mathrm{TM}}$ assay further confirmed the functional activity of transcribed genes upon co-treatment. When the anticancer agents (doxorubicin, paclitaxel, tamoxifen or vinblastine) were combined with ritonavir, a significantly diminished cell proliferation and migration and augmented caspase activity leading to apoptosis was observed in T47D and PC-3 cells.

Conclusions: Combination therapy of anticancer drug with ritonavir may overcome drug resistance by deactivating the overexpression of efflux transporters and metabolizing enzymes. Therefore, drug regimens containing ritonavir would enhance therapeutic exposure of cancer cells to anticancer agents, potentially improving chemotherapeutic efficacy and consequently devoid of resistance.

Keywords: Multidrug resistance; Efflux; Metabolism; Ritonavir; Anticancer drugs; Chemotherapy

\section{Introduction}

Despite complex nature of cancer, tremendous advancements in cancer treatment have been made in the recent years. Chemotherapy represents the most common treatment modalities for cancer treatment. However, a major impediment to successful chemotherapy is the development of multidrug resistance (MDR) where resistance to one drug often confers resistance to several structurally and functionally unrelated drugs [1-3]. Many treatment modalities impose three to four drugs simultaneously. Patients in the early stage of cancer respond quickly, however, due to the development of drug resistance, cancer cells adapt treatment and relapse by overcoming therapy. Resistance to chemotherapy can either be intrinsic (resistance exists before the drug treatment is initiated) or acquired (resistance develops during drug treatment) [4]. Mechanisms of drug resistance are very complex. Several possible mechanisms and molecular alterations have been implicated in the development of MDR, including activation of drug transporters and metabolizing enzymes, mutation and amplification of drug targets, tumor microenvironment conditions (hypoxic conditions leading to vascularization) and genetic rewiring leading to cellular repair mechanisms (activation of DNA repair, mutant p53 and impaired apoptosis) [5].

Entry of drug molecules is dependent on their chemical nature; some drugs utilize drug-transporters/receptors while others cross the cell membrane by facilitated diffusion. A key to successful chemotherapy is the availability of drugs at therapeutic concentrations in the target cancer cells. Efflux transporters and metabolizing enzymes play a vital role in regulating intracellular drug accumulation [6]. The ATP-binding cassette (ABC) family includes almost 48 structurally related transmembrane proteins which play a key role in regulating translocation of various drugs, toxins, endogenous peptides and cellular lipids [7]. Fifteen members of these ABC transporters are associated with the development of MDR. Among these, three efflux transporters including P-glycoprotein (P-gp/MDR1), multidrug resistance protein 2 (MRP2) and breast cancer resistant protein or mitoxantrone resistance protein (BCRP/MXR) play a predominant role. In response to chemotherapy, efflux transporters are overexpressed which prevent drug accumulation by extruding therapeutic agents from the cells, resulting in sub-therapeutic concentration [8]. Also, metabolizing enzymes such as cytochrome P450 (CYP450) are induced in response to many anticancer drugs causing rapid biotransformation of active molecule and resulting in treatment failure [3]. Also, chemotherapeutic agents require enzymatic activation for biotransformation to exert

*Corresponding author: Dhananjay Pal, Associate Research Professor, University of Missouri-Kansas City, School of Pharmacy, 2464 Charlotte Street, HSB 5252, Kansas City, MO 64108-2718, USA, Tel: 816-235-2431; Fax: 816-2355779; E-mail: pald@umkc.edu

Received July 17, 2014; Accepted October 22, 2014; Published October 25 , 2014

Citation: Vadlapatla RK, Pal D, Vadlapudi AD Mitra AK (2014) Ritonavir: A Powerfu Boosting Agent for Overcoming Drug Resistance in Cancer Chemotherapy. J Cancer Sci Ther 6: 446-454. doi:10.4172/1948-5956.1000307

Copyright: ( 2014 Vadlapatla RK, et al. This is an open-access article distributed under the terms of the Creative Commons Attribution License, which permits unrestricted use, distribution, and reproduction in any medium, provided the original author and source are credited. 
their cytotoxic effect. For example, the nucleoside drug cytarabine (extensively administered for leukemia) requires phosphorylation by deoxycytidine kinase to convert to active form cytarabine triphosphate. To reduce the drug effect, cancer cells acquire resistance by decreasing drug activation. Such resistance develops via downregulation/mutation of the respective metabolic enzyme [9-10]. Two recent review articles have discussed mechanisms and insights of drug resistance in cancer $[3,11]$.

Two main approaches have been explored so far to overcome efflux pumps and metabolizing enzymes. These include either coadministering a drug with an efflux modulator or employing anticancer agents which are not substrates of efflux transporters. Such modulators are categorized into first, second and third generations. First generation modulators include verapamil and cyclosporine A, which requires usage of very high doses leading to undesirable side effects and toxicity. The second generation modulators such as dexverapamil and valspodar were found to be potent. These drugs act by inhibition of cytochrome P450 (CYP450). This change in activity leads to altered pharmacokinetics of co-administered drugs, often raising their systemic toxicity. Then, third generation modulators such as tariquidar and zosuquidar are designed with the aid of combinatorial chemistry to overcome these barriers [12-13]. These modulators act on efflux transporter at substrate binding sites. Unfortunately there are no modulators, so far identified, which can act at molecular level to prevent activation of MDR gene and metabolizing enzymes simultaneously. A novel common modulator which can inhibit the resistance mechanisms (i.e. activation of efflux transporters and metabolizing enzymes) needs to be explored for successful chemotherapy.

Drug resistance in HIV patients is also well known. Protease inhibitors (PIs) play an instrumental role in reducing AIDS-related mortality and morbidity [14]. The treatment protocol of highly active antiretroviral therapy (HAART) involves a combination of two PIs in the dosing regimen which plays a pivotal role in overcoming drug resistance. Pharmacokinetic 'boosting' - particularly the use of ritonavir to enhance the concentration of coadministered PI (e.g. lopinavir) in the regimen has tremendous effect. Ritonavir is a perfect pharmacokinetic enhancer because it inhibits first-pass metabolism during intestinal absorption, prevents P-gp-mediated drug efflux and inhibits CYP3A4 in the liver [15]. Such inhibition of efflux pumps and CYP3A4 by ritonavir forms the basis for its enhancement of concomitantly administered drugs in HAART. These combinations may enable higher sustained levels of the second PI. Such regimens have been utilized to overcome resistance and allow less frequent dosing and potentially improving adherence. This combination has been clinically proven to be highly beneficial for HIV infected individuals. Increased transcription of P-gp and CYP3A4 which is regulated by pregnane $\mathrm{X}$ receptor (PXR) can also be controlled by coadministering with ritonavir. When ritonavir was used along with rifampicin (a strong inducer of PXR), the extent of CYP3A4 activity (synthesis) was substantially reduced compared to rifampicin alone.

To overcome drug resistance, it is necessary to achieve high plasma drug concentrations to prevent HIV replication. If the plasma concentration of therapeutic agents is not high enough, viruses continue to replicate and possibly subsidize drug resistance. However, the drug concentration should not be too high which may result in toxicity. This balance is seen in Kaletra with $400 \mathrm{mg}$ of lopinavir plus $100 \mathrm{mg}$ of ritonavir or $500 \mathrm{mg}$ of lopinavir plus $125 \mathrm{mg}$ of ritonavir along with nucleoside reverse transcriptase inhibitor or non-nucleoside reverse transcriptase inhibitor. Such dosing regimens of PIs prevent drug resistance in HIV. Among several PI combinations tested, ritonavir with another PI appears to be the most potent combination to eradicate HIV replication. Therefore, a similar hypothesis can be postulated to overcome drug resistance in cancer employing ritonavir in combination with an anticancer drug. This hypothesis has been examined in vitro to demonstrate and to predict if the antitumor activity of anticancer drugs can be enhanced by coadministration of ritonavir. Human colon adenocarcinoma (LS180) cells have been selected to study the expression levels of efflux transporters (MDR1, MRP2), metabolizing enzyme (CYP3A4) and nuclear receptor (PXR) employing vinblastine as a model drug. Various efficacy studies such as cell proliferation, migration and apoptosis have been performed using several anticancer drugs (doxorubicin, paclitaxel, tamoxifen and vinblastine) and in combination with ritonavir. Efficacy studies of such combinations were performed on human breast adenocarcinoma cells (T47D) and prostate cancer cells (PC-3) due to their aggressive phenotypic nature.

\section{Materials and Methods}

\section{Materials}

Doxorubicin, paclitaxel, tamoxifen, vinblastine and ritonavir were obtained from Sigma-Aldrich -Aldrich (St. Louis, MO). LS180, T47D and PC-3 cells were procured from American Type Culture Collection (ATCC) (Manassas, VA). $\left[{ }^{3} \mathrm{H}\right]$ Lopinavir (specific activity: $0.5 \mathrm{Ci} / \mathrm{mMol}$ ) was purchased from Moravek Biochemicals (Brea, CA). Dulbecco's modified eagle medium (DMEM), Roswell Park Memorial Institute (RPMI) 1640 medium, stable trypsin replacement (TrypLE ${ }^{\mathrm{mw}}$ Express), non-essential amino acids and Vivid" CYP450 screening kit were obtained from Invitrogen (Carlsbad, CA). Fetal bovine serum (FBS) was purchased from Atlanta Biologicals (Lawrenceville, GA) Culture flasks ( $75 \mathrm{~cm}^{2}$ and $25 \mathrm{~cm}^{2}$ growth area), 12-well plates $\left(3.8 \mathrm{~cm}^{2}\right.$ growth area per well) and 96 -well plates $\left(0.32 \mathrm{~cm}^{2}\right.$ growth area per well) were purchased from Corning Costar Corp. (Cambridge, MA). The buffers for cDNA synthesis (OligodT, dNTP, $\mathrm{MgCl}_{2}$, M-MLV reverse transcriptase), CellTiter $96^{\circ}$ non-radioactive cell proliferation assay and ApoONE ${ }^{\circ}$ homogeneous caspase-3/7 assay kit were obtained from Promega Corporation (Madison, WI). Light Cycler $480^{\circ}$ SYBR I green master mix was obtained from Roche Applied Science (Indianapolis, IN). QCM 24-well colorimetric cell migration assay kit was purchased from Millipore (Billerica, MA). BCA protein assay reagent was purchased from Thermo Fisher Scientific Inc (Rockford, IL). TRI Reagent and all other chemicals were products of commercial grade purchased from Sigma-Aldrich and used without further purification.

\section{Cell culture}

LS180 and T47D cells were maintained in T-75 flasks at $37^{\circ} \mathrm{C}$ in a humidified atmosphere of $5 \% \mathrm{CO}_{2}$ and $90 \%$ relative humidity with DMEM medium supplemented with 10\% FBS (heat inactivated), $1 \%$ non-essential amino acids, $20 \mathrm{mM}$ HEPES, $29 \mathrm{mM}$ sodium bicarbonate and $100 \mu \mathrm{g} / \mathrm{ml}$ of penicillin and streptomycin. PC-3 cells were maintained in RPMI 1640, supplemented with 10\% FBS (nonheat inactivated), $15 \mathrm{mM}$ HEPES, $24 \mathrm{mM}$ sodium bicarbonate and 100 $\mu \mathrm{g} / \mathrm{ml}$ of penicillin and streptomycin. The medium was replaced every alternate day. Cells were passaged using TrypLE" Express, after reaching $80-90 \%$ confluence. Subsequently, cells were seeded at a density of $1,000,000$ cells in $25 \mathrm{~cm}^{2}$ flasks, 250,000 cells/well in 12-well plates and 10,000 cells/well in 96-well plates. Drug solution stocks were prepared in dimethyl sulfoxide (DMSO) and sterile filtered using $0.22 \mu \mathrm{m}$ filters. Prior to initiation of a treatment, stocks of drug solutions were diluted in appropriate volume of the medium and final concentration 
of DMSO did not exceed $0.5 \%(\mathrm{v} / \mathrm{v})$. LS180 cells were used for gene expression and functional activity studies. T47D and PC-3 cells were used for efficacy studies upon co-treatment.

\section{Quantitative gene expression studies}

LS180 cells were treated for 72 hours with vinblastine alone and in the presence of different concentrations of ritonavir. The concentration of vinblastine $(0.1 \mu \mathrm{M})$ was determined from previously published results [16]. Ritonavir concentrations ranging from $1 / 8$ th $-1 / 2$ nd of vinblastine dose were selected to determine the optimal booster dose. Following treatment, RNA was extracted from cells using TRI' reagent following manufacturer's protocol. Cells were lysed in phenol and chloroform was added for phase separation. The aqueous phase containing RNA was collected and $100 \%$ isopropanol was added to precipitate RNA. The pellet was washed with $75 \%$ ethanol and dissolved in DNase/RNase-free water. RNA concentration was quantified using Nanodrop (Thermo Fisher Scientific, Wilmington, DE). Two microgram of RNA was reverse transcribed with oligodT as template using M-MLV reverse transcriptase. The conditions for reverse transcription were initial denaturation at $70^{\circ} \mathrm{C}$ for $5 \mathrm{~min}$, reverse transcription at $42^{\circ} \mathrm{C}$ for 1 hour and final extension at $72^{\circ} \mathrm{C}$ for $5 \mathrm{~min}$. For quantitative gene expression analysis, $80 \mu \mathrm{g}$ of cDNA was amplified using SYBR-green master mix on ABI Prism 5700 Sequence Detection System (Applied Biosystems). Primers were designed with Primer Blast tool from PubMed and are summarized in Supplementary Table 1. The reactions were carried out with initial denaturation at $70^{\circ} \mathrm{C}$ for $5 \mathrm{~min}$, followed by 45 cycles of denaturation at $95^{\circ} \mathrm{C}$ for $10 \mathrm{sec}$, annealing at $55^{\circ} \mathrm{C}$ for $10 \mathrm{sec}$ and extension at $72^{\circ} \mathrm{C}$ for $10 \mathrm{sec}$. PCR specificity was confirmed by melting curve analysis. Relative amount of RNA levels was normalized to the internal standard GAPDH (Glyceraldehyde 3-phosphate dehydrogenase) in each sample. Any difference in RNA levels in treated vs control samples was quantified using modified ddCT method [17-19].

\section{Immunoblot analysis}

After 72 hours treatment with different drug solutions, LS180 cells were washed with PBS $\left(3.2 \mathrm{mM} \mathrm{Na}_{2} \mathrm{HPO}_{4}, 0.5 \mathrm{mM} \mathrm{KH}_{2} \mathrm{PO}_{4}, 1.3 \mathrm{mM}\right.$ $\mathrm{KCl}, 135 \mathrm{mM} \mathrm{NaCl}$ ) and lysed in PBS with $1 \%$ Triton X-100 and protease inhibitor cocktail maintained at $\mathrm{pH} 7.4$, for 15-20 min on ice. Upon homogenization, cells were centrifuged at $12,000 \mathrm{rpm}$ for $10 \mathrm{~min}$ and the protein lysate was collected. The amount of protein in the lysate was determined using BCA protein assay reagent. An equivalent amount of protein $(25 \mu \mathrm{g})$ in all samples was separated with polyacrylamide gel electrophoresis (PAGE). The protein was then transferred onto a polyvinylidene difluoride (PVDF) membrane and blocked overnight at $4^{\circ} \mathrm{C}$ with $2 \%$ non-fat dry milk and $0.25 \%$ BSA prepared in 0.05 $\mathrm{M}$ tris buffered saline. The blot was then exposed to primary P-gp antibody (Abcam, MA) at $37^{\circ} \mathrm{C}$ for 4 hours. After subsequent washes, the blot was then exposed to secondary antibody-goat anti rabbit HRP conjugate (Santa Cruz Biotechnology, Inc., CA). Finally the blot was visualized for the protein band using chemiluminescent substrate (Pierce Biotechnology, IL) in chemiImager 8900 (Alpha Innotech, CA).

\section{Uptake study}

Uptake of $\left[{ }^{3} \mathrm{H}\right]$ Lopinavir was conducted to confirm the functional activity of MDR1/P-gp. This study was carried out in LS180 cells cultured in 12-well plates. After treatment with drug solutions for 72 hours, the drug solutions were aspirated and cells were washed twice with $2 \mathrm{ml}$ of Dulbecco's phosphate-buffered saline (DPBS - $30 \mathrm{mM}$ $\mathrm{NaCl}, 2.5 \mathrm{mM} \mathrm{KCl}, 7.5 \mathrm{mM} \mathrm{Na}_{2} \mathrm{HPO}_{4}, 1.5 \mathrm{mM} \mathrm{KH}_{2} \mathrm{PO}_{4}, 1 \mathrm{mM} \mathrm{CaCl}$,
$0.5 \mathrm{mM} \mathrm{MgSO}_{4}, 5 \mathrm{mM}$ glucose and $20 \mathrm{mM}$ HEPES) at $\mathrm{pH} 7.4$ for 10 min. Later, uptake was initiated by adding $0.5 \mathrm{ml}$ of $\left[{ }^{3} \mathrm{H}\right]$ Lopinavir $(0.5 \mu \mathrm{Ci} / \mathrm{ml})$ into the wells. After $30 \mathrm{~min}$ of incubation, solution was removed and uptake was terminated with ice-cold stop solution (200 $\mathrm{mM} \mathrm{KCl}$ and $2 \mathrm{mM}$ HEPES) and rinsed $3 \mathrm{X} 5 \mathrm{~min}$ with the same buffer to remove the surface bound drug. Cells were lysed overnight at $25^{\circ} \mathrm{C}$ using lysis solution $(0.1 \%(\mathrm{v} / \mathrm{v})$ Triton-X in $0.3 \mathrm{~N} \mathrm{NaOH})$. Cell lysate was then quantified for radioactivity with a scintillation counter (Beckman Counter, CA). The amount of radioactivity was normalized to protein count and analyzed following previously published methods [17-19].

\section{Vivid" fluorescent assay}

This assay was performed on LS180 cells cultured in 96-well plate. Cells were treated with $100 \mu$ of drug solutions $(0.1 \mu \mathrm{M}$ vinblastine alone and in presence of $25 \mathrm{nM}$ ritonavir) for 72 hours and subsequently lysed with $100 \mu \mathrm{l}$ of lysis solution. Forty microliters of cell lysate was then added to $60 \mu$ lof master mix containing VIVID" Red Substrate. The metabolite formed is highly fluorescent and dependent upon cellular CYP3A4 levels. After 30 min incubation, the fluorescent readings were monitored at an excitation wavelength of $530 \mathrm{~nm}$ and an emission wavelength of $585 \mathrm{~nm}$ by a microtiter plate reader (SpectraFluor Plus, Maennedorf, Switzerland). The readings were then normalized to protein count as described earlier.

\section{Cell proliferative assay}

This study was performed on human breast adenocarcinoma cells (T47D) and prostate cancer cells (PC-3) to determine the $\mathrm{IC}_{50}$ value (half maximal inhibitory concentration) of chemotherapeutic drugs (doxorubicin, paclitaxel, tamoxifen and vinblastine) alone, and in the presence of ritonavir. T47D /PC-3 cells were seeded in 96-well plates and cultured for 24 hours, before the initiation of treatment. Later, medium was aspirated and cells were treated with various concentrations of drug alone and in the presence of ritonavir for 72 hours. The drug solutions were then aspirated and $100 \mu \mathrm{l}$ of serum free media was added. Subsequently, $20 \mu$ of MTS and PMS reagents were added to the wells. After incubating for 3 hours, the quantity of formazan product was measured at $490 \mathrm{~nm}$ with a plate reader. The amount of formazan formed from dehydrogenase enzymes is directly proportional to the number of viable cells. Data was fitted to a transformed nonlinear regression curve analysis program (GraphPad Prism Version 4.0; GraphPad Software, Inc., CA) to calculate $\mathrm{IC}_{50}$ value.

\section{Migration assay}

This assay was performed in modified Boyden's insert, where cells from an upper compartment were allowed to migrate into a lower compartment across the microporous membrane in the presence of a chemoattractant. Briefly, T47D and PC-3 cells pretreated with various drug solutions were serum starved for 16 hours. Later, $300 \mu \mathrm{l}$ of cell suspension $(1 \mathrm{million} / \mathrm{ml})$ in serum free media was seeded in the upper compartment and $500 \mu \mathrm{l}$ of $10 \%$ serum media was added to the lower compartment. This gradient in serum concentration acts as a driving force for cells to migrate. The cells that had migrated into lower compartment were then incubated with a cell stain solution, subsequently extracted using an extraction reagent and quantified by measuring the absorbance at $560 \mathrm{~nm}$.

\section{Apoptosis (caspase-3/7 assay)}

This assay was used to determine the apoptotic induction of chemotherapeutic drugs alone and in the presence of ritonavir. The 
assay consists of a pro-fluorescent substrate which when cleaved by caspases-3/7 produces fluorescent rhodamine. The amount of fluorescence produced is proportional to the extent of apoptosis in cells. This assay was performed in 96-well plates. After treating the cells, drug solutions were aspirated and $100 \mu \mathrm{l}$ of serum free media was added. After this, equal volume of caspase buffer with substrate was added. The contents were gently mixed in a plate shaker for $1 \mathrm{~min}$ and incubated for 2 hours at room temperature. Later, the fluorescent readings were monitored at an excitation wavelength of $485 \mathrm{~nm}$ and an emission wavelength of $527 \mathrm{~nm}$ with a microtiter plate reader.

\section{Statistical analysis}

All the experiments were conducted at least in quadruplicate (n $=4$ ), and results were expressed as mean \pm standard deviation (SD). Statistical comparison of mean values was performed with one-way analysis of variance (ANOVA) or a Student's t test. A P-value of less than 0.05 was considered to be statistically significant and represented by an asterisk $\left.{ }^{*}\right)$.

\section{Results}

\section{Gene expression analysis}

Vinblastine $(0.1 \mu \mathrm{M})$ alone caused 7 fold enhancement of MDR1 mRNA expression in LS180 cells. Such induction by vinblastine was, however, significantly lowered in the presence of ritonavir $(25 \mathrm{nM}$, $30 \mathrm{nM}$ and $35 \mathrm{nM}$ ). An equivalent to $1 / 4$ th of vinblastine dose i.e. 25 $\mathrm{nM}$ concentration of ritonavir was required to overcome vinblastine mediated overexpression of MDR1 and to maintain basal level of expression (Figure 1A). Hence, this concentration was selected as optimal booster dose for all further experiments. Vinblastine $(0.1$ $\mu \mathrm{M})$ exhibited 8 fold induction of MRP2 expression level which was significantly diminished in the presence of $25 \mathrm{nM}$ ritonavir (Figure 1B). Vinblastine $(0.1 \mu \mathrm{M})$ alone produced 40 fold induction in CYP3A4
mRNA levels which was completely abolished in the presence of $25 \mathrm{nM}$ ritonavir (Figure $1 \mathrm{C})$. Vinblastine $(0.1 \mu \mathrm{M})$ induced overexpression of PXR-mRNA was reduced to half, when vinblastine and ritonavir were given together (Figure 1D).

\section{Protein expression analysis}

LS180 cells were treated with vinblastine alone and in the presence of optimal ritonavir dose $(25 \mathrm{nM})$ for 72 hours. The relative fold induction of P-gp protein expression was determined by immunoblot analysis. Vinblastine showed very high induction of P-gp protein level which was compromised to normal level when cells were treated with $0.1 \mu \mathrm{M}$ vinblastine along with $25 \mathrm{nM}$ ritonavir (Figure 2).

\section{Functional activity studies}

Lopinavir is a well-known substrate for both P-gp and MRP2 efflux pumps [20]. To evaluate the functional activity of the efflux pumps upon treatment, uptake of $\left[{ }^{3} \mathrm{H}\right]$ Lopinavir was quantified on LS180 cells. In vinblastine treated cells, the uptake of $\left[{ }^{3} \mathrm{H}\right]$ Lopinavir was significantly lower compared to control indicating enhanced activity of efflux pumps. In cells treated with $0.1 \mu \mathrm{M}$ vinblastine with $25 \mathrm{nM}$ ritonavir, this uptake was comparable to control, showing reduced activity of efflux pumps with co-treatment (Figure 3A). To study the functional activity of CYP3A4 gene, vivid assay was performed following drug treatment. The amount of metabolite formed from the substrate is dependent on levels of CYP3A4 activity in the cells. Compared to control cells, vinblastine treated cells showed $80 \%$ increase in metabolite formation which confirms high CYP3A4 activity. However, such CYP3A4 activity was significantly diminished comparable to control, in cells co-treated with vinblastine and ritonavir. This CYP3A4 activity correlates with gene expression analysis (Figure 3B).

\section{Cell proliferation assay}

MTS assay was performed to determine inhibitory effect of
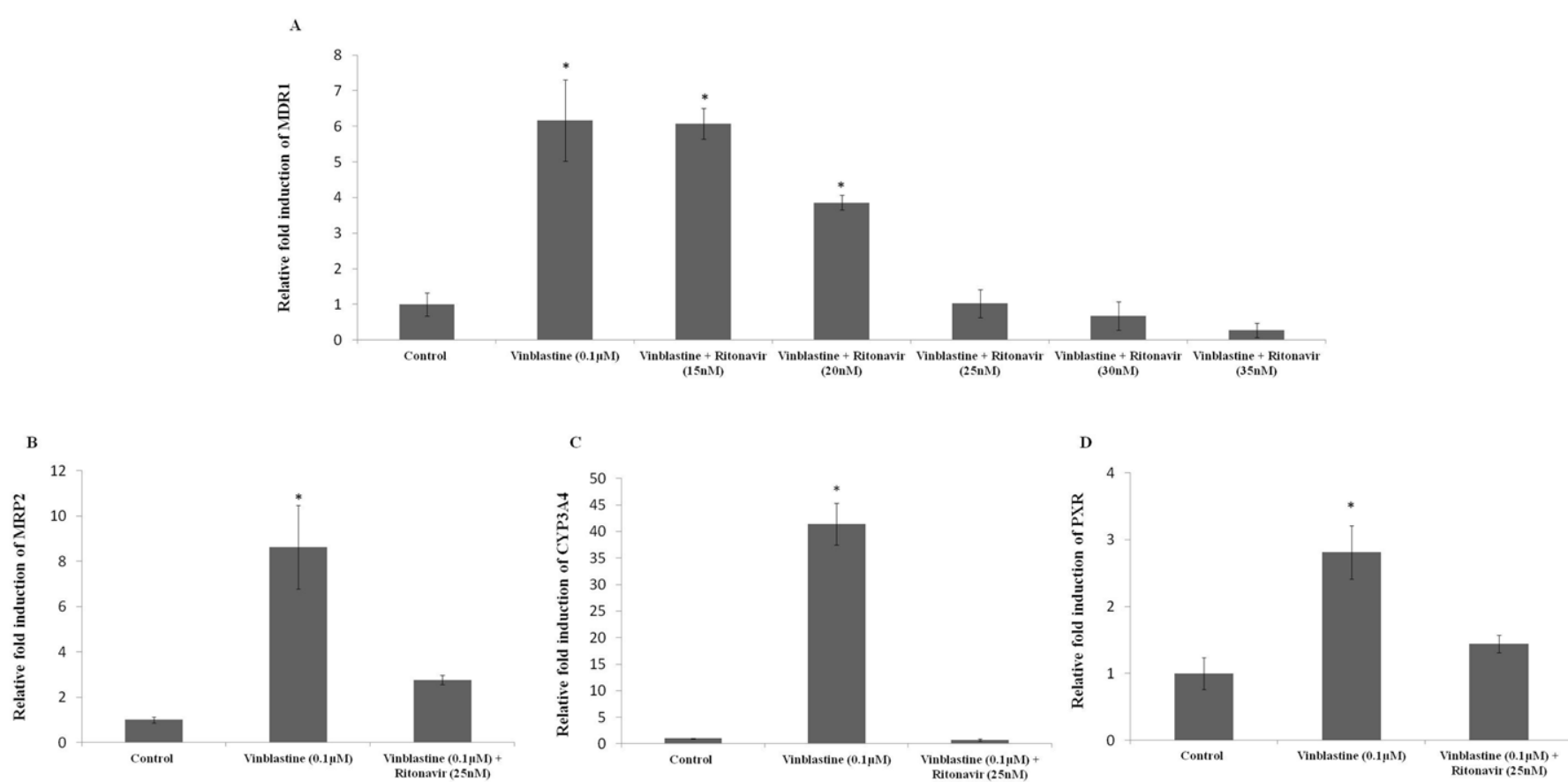

Figure 1: Relative fold induction of (A) MDR1 gene post treatment with vinblastine alone and in the presence of different concentrations of ritonavir, (B) MRP2, (C) CYP3A4 and (D) PXR genes post treatment with vinblastine alone and in the presence of optimized concentration of ritonavir on LS180 cells. Values represent mean \pm SD $(n=4)$. A P-value of less than 0.05 was considered to be statistically significant and represented by *. 


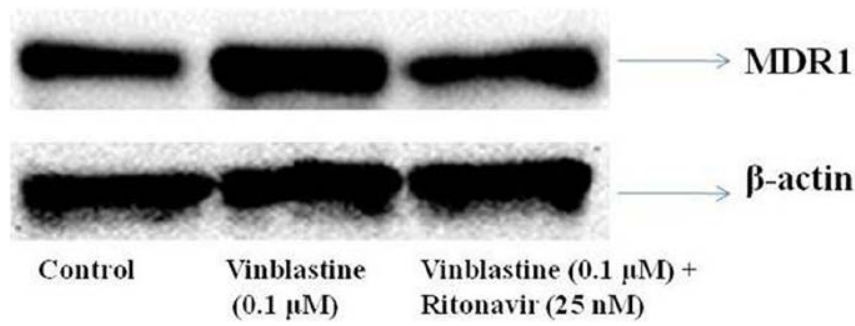

Figure 2: Immunoblot analysis showing the induction of MDR1 post treatment with vinblastine alone and in the presence of optimized concentration of ritonavir on LS180 cells. $\beta$-actin was used as an internal control.
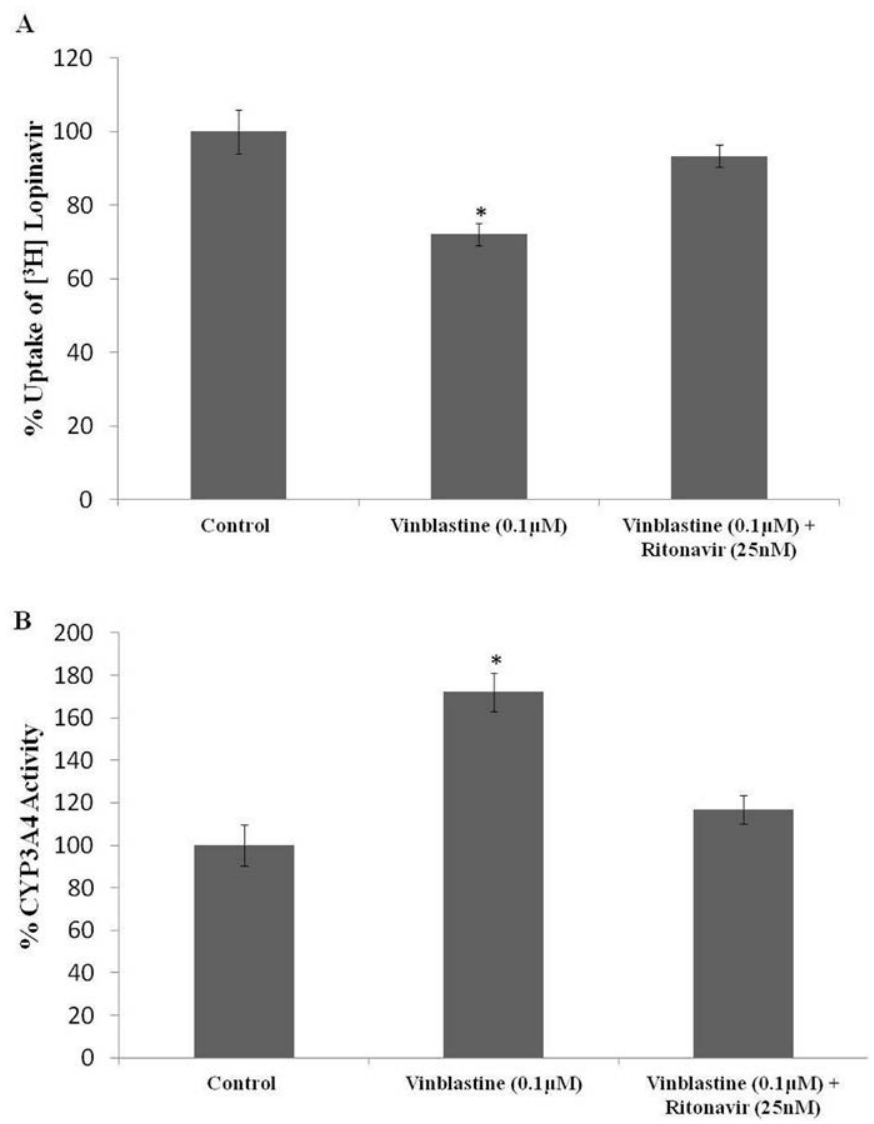

Figure 3: (A) Uptake of $[3 \mathrm{H}]$ lopinavir $(0.5 \mu \mathrm{Ci} / \mathrm{mL})$ on $\mathrm{LS} 180$ cells post treatment with vinblastine alone and in the presence of optimized concentration of ritonavir. (B) Percentage CYP3A4 activity as estimated by formation of fluorescent substrate from LS180 cells post treatment with vinblastine alone and in the presence of optimized concentration of ritonavir. Values represent mean \pm standard SD $(n=4)$. A P-value of less than 0.05 was considered to be statistically significant and represented by *

chemotherapeutic agents (doxorubicin, paclitaxel, tamoxifen, and vinblastine) alone and in the presence of ritonavir in T47D cells. $\mathrm{IC}_{50}$ values of doxorubicin and tamoxifen $(478 \pm 13 \mathrm{nM}$ and $3.5 \pm 1.1 \mu \mathrm{M})$ were reduced by almost three fold $(167 \pm 14 \mathrm{nM}$ and $1.1 \pm 0.6 \mu \mathrm{M})$ in the presence of ritonavir. Similarly, presence of ritonavir lowered $\mathrm{IC}_{50}$ of paclitaxel $(3.3 \pm 1.2 \mathrm{nM})$ by almost four fold $(0.9 \pm 0.4 \mathrm{nM}) . \mathrm{IC}_{50}$ of vinblastine was observed to be $10.81 \pm 1.38 \mathrm{nM}$. This $\mathrm{IC}_{50}$ value was diminished by seven fold in the presence of ritonavir to $1.44 \pm 0.45 \mathrm{nM}$ (Figure 4A-4D). These results show that ritonavir enhanced the ability of all chemotherapeutics to inhibit cell growth.

\section{Cell migration assay}

T47D cells pretreated with drug solutions were serum starved for 16 hours. The relative numbers of cells that migrated towards $10 \%$ serum media were estimated by a spectrophotometer. The numbers of cells that had migrated were reduced by $10-40 \%$ in cells treated with chemotherapeutics alone. This reduction was further enhanced to almost 1.5-2 fold in cells co-treated with ritonavir (Figure 5A-5D).

\section{Apoptosis (caspase-3/7) assay}

This assay was performed to determine levels of apoptosis in T47D cells in the presence of anticancer agents alone and with ritonavir. The chemotherapeutics alone induced apoptosis by approximately 3-4.5 fold and this value was further enhanced by almost two fold in the presence of ritonavir. The co-treated cells exhibited increased levels of apoptosis (Figure 6A-6D). The relative levels of cell proliferation, migration and apoptosis in T47D and PC-3 cells treated with different chemotherapeutics alone or in the presence of ritonavir were summarized in Supplementary Tables 2 and 3, respectively.

\section{Discussion}

Riddick DS et al. [21] indicated that drug transport and metabolism are dominant determinants of antineoplastic drug pharmacokinetics and pharmacodynamics. Modulation of these processes should be exploited appropriately for therapeutic advantages. The primary objective of our study was to develop a strategy to overcome drug resistance and enhance antitumor activity of conventional anticancer agents. In our studies, we have selected some common anticancer agents (doxorubicin, paclitaxel, tamoxifen and vinblastine) along with a PI ritonavir to demonstrate the hypothesis that inclusion of ritonavir with these chemotherapy agents can enhance antitumor activity by circumventing efflux and metabolism.

LS180 cells have been shown to be an excellent model to predict long term drug-drug interactions mediated by inductions of efflux transporters and metabolizing enzymes [22,23]. Vinblastine - a substrate of both efflux transporters and metabolizing enzyme was chosen as a model anticancer drug. Prolonged exposure to vinblastine is known to induce efflux transporters and metabolizing enzymes [16]. Overexpression of MDR1 is considered to be a major contributor to drug resistance. In order to counteract the vinblastine mediated inductions of efflux transporters and metabolizing enzymes, ritonavir, which is a known substrate and inhibitor was selected. Dose dependent studies on LS180 cells were performed to optimize ritonavir dose and to evaluate the induction potential of MDR1 gene upon cotreatment. Presence of ritonavir at various concentrations $(25 \mathrm{nM}, 30 \mathrm{nM}$ and 35 $\mathrm{nM}$ ) demonstrated a significant lowering of MDR1 overexpression caused by vinblastine (Figure 1). The lowest concentration i.e. $25 \mathrm{nM}$ which was adequate to completely counteract such overexpression of MDR1 was selected for all further studies. Treatment of LS180 cells with vinblastine alone and in the presence of $25 \mathrm{nM}$ ritonavir for 72 hours, also counteracted overexpression of MRP2 (8 fold) and CYP3A4 (40 fold) (Figures $1 \mathrm{~b}$ and $1 \mathrm{c}$ ) and the gene expression levels almost reached to the endogenous control levels of their respective genes. PXR belongs to a nuclear receptor super family whose primary function is to sense the presence of foreign toxic substances and to respond by upregulating genes involved in detoxification and clearance of such substances. Induction of PXR by vinblastine was substantially diminished in the presence of ritonavir (Figure 1D). Results from these experiments clearly suggest that ritonavir has the ability to block vinblastine-induced overexpression of PXR and consequently MDR1, MRP2, and CYP3A4 at the transcriptional level. 

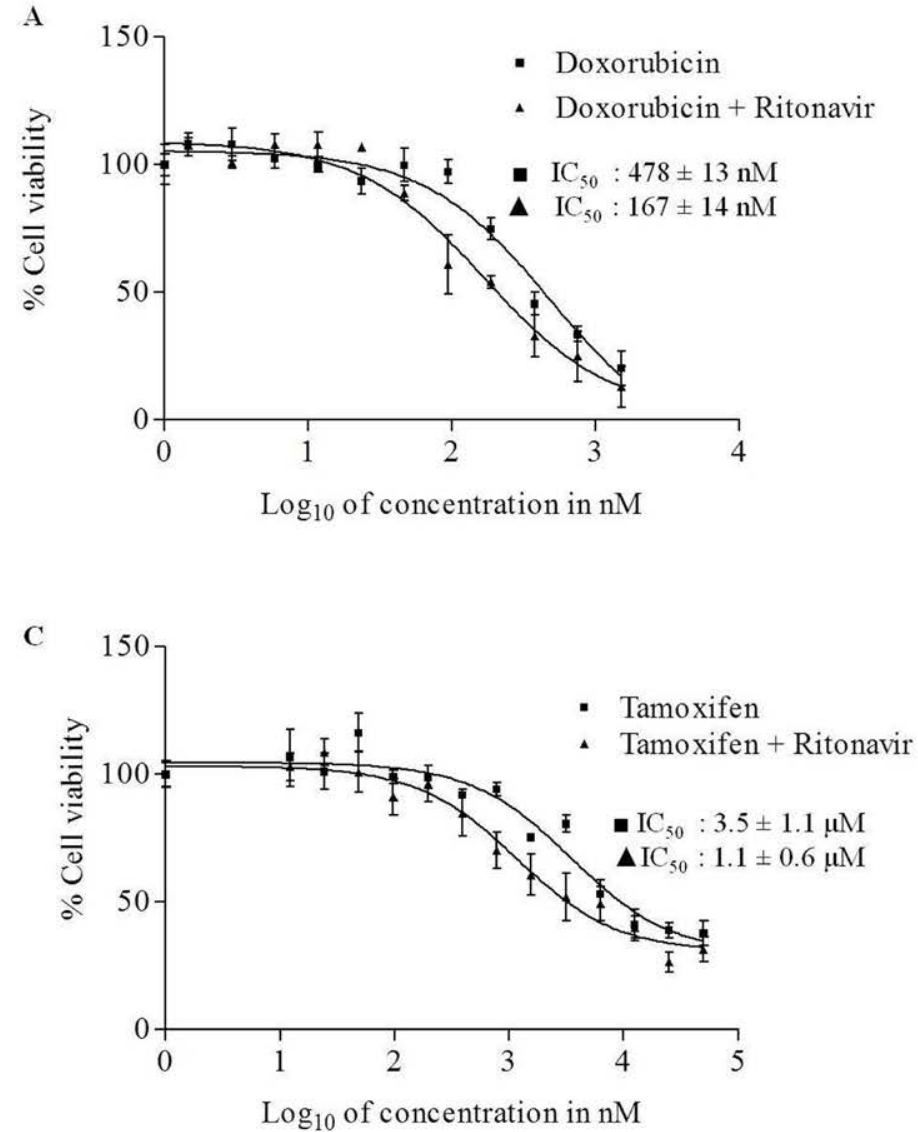
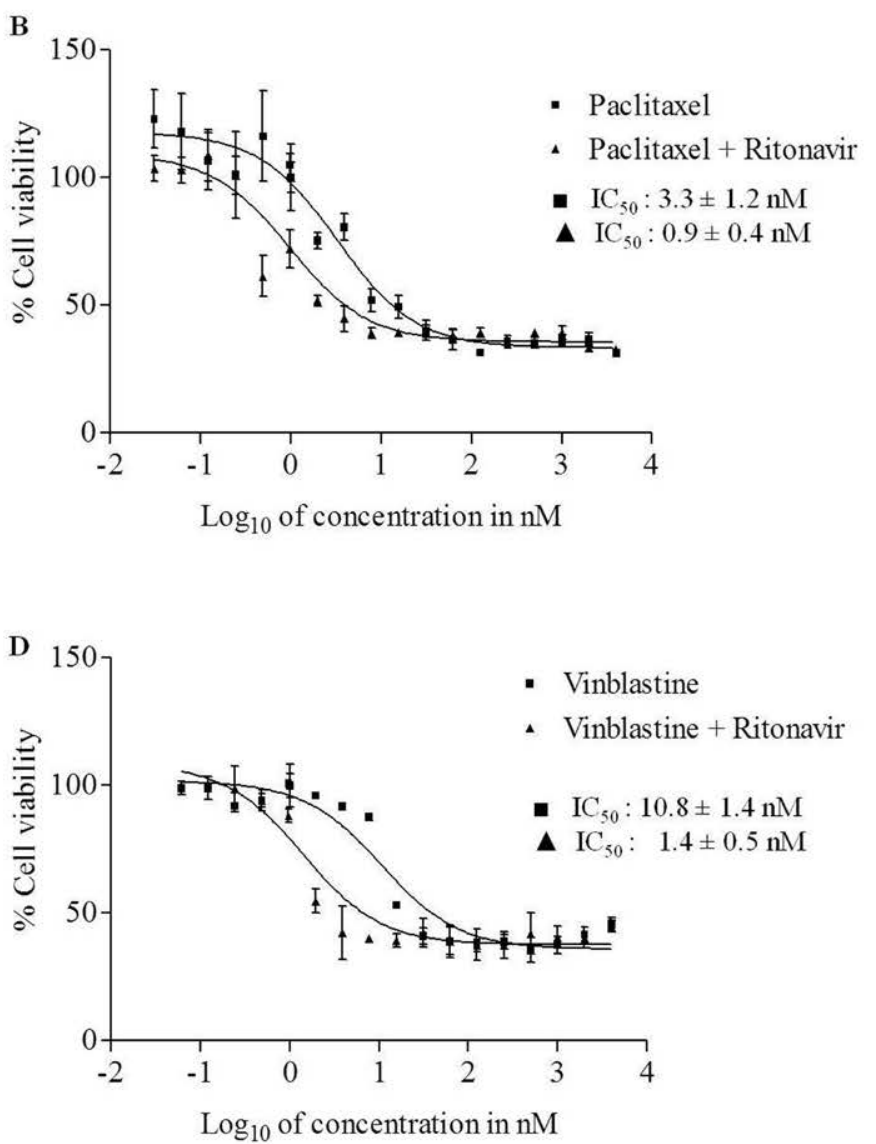

Figure 4: Percent viability of T47D cells treated with different concentrations of chemotherapeutic drugs alone and in the presence of ritonavir for 72 hours. Data represent mean percentage of viable cells $\pm \operatorname{SD}(n=6)$.

To evaluate if the induction of efflux transporters and metabolizing enzyme at the transcriptional level correlates to the protein expression and activity, immunoblot and functional activity studies were performed, respectively. Immunoblot analysis confirmed the induction of P-gp by vinblastine alone. The broad protein band in the blot which appears in response to vinblastine treatment is diminished when cells were co-treated with vinblastine and ritonavir (Figure 3). This result corroborates with gene expression studies as described earlier. Also reduced intracellular accumulation of $\left[{ }^{3} \mathrm{H}\right]$ Lopinavir, a substrate for P-gp-mediated efflux, in vinblastine treated cells confirms the enhanced functional activity of transcribed efflux transporter. In contrast, unchanged $\left[{ }^{3} \mathrm{H}\right]$ Lopinavir uptake, comparable to control, in response to vinblastine plus ritonavir suggests that ritonavir can completely reverse vinblastine-mediated over activity of efflux transporter (Figure 3A). An increase in CYP3A4 activity following vinblastine treatment correlates well with the mRNA levels. Although, functional activity was elevated only by about 1.7 times compared to 40 fold mRNA induction. It appears that just 72hours exposure may not be sufficient to generate full functional CYP3A4 activity. However, elevated activity of CYP3A4 significantly reflects with increased metabolite formation (Figure $3 \mathrm{~B}$ ). Such enhanced CYP3A4 activity was not observed when the LS180 cells were treated with vinblastine along with ritonavir. VIVID assay results clearly suggest that ritonavir can prevent vinblastine-induced over activity of CYP3A4.

With the encouraging results from gene and protein expression analysis, three other chemotherapeutics (doxorubicin, paclitaxel, tamoxifen and vinblastine) were further tested in combination with ritonavir for different efficacy studies: cell proliferation, migration and apoptosis employing breast (T47D) and prostate cancer (PC-3) cells. Although gene and protein expression studies were conducted on LS180 cells, efficacy studies were performed on T47D and PC-3 cells due to their aggressive phenotypic nature. $\mathrm{IC}_{50}$ values of all four drugs (doxorubicin, paclitaxel, tamoxifen and vinblastine) were significantly reduced by 3-7 folds in the presence of ritonavir (Figure 4A-4D, Supplementary Tables 1 and 2). In fact, IC $_{50}$ of vinblastine was $10.81 \pm$ $1.38 \mathrm{nM}$ for T47D cells. This value was diminished by seven fold in the presence of ritonavir to $1.44 \pm 0.45 \mathrm{nM}$ (Figure $4 \mathrm{D}$ ). A similar result was found in PC3 cells also. These results clearly indicate that ritonavir in combination with chemotherapeutics can significantly enhance the antitumor efficacy and prevent proliferation of cancer cells. Recent studies have shown that PIs possess anti-proliferative activity. Ritonavir alone inhibited Akt-mediated cell proliferation in breast cancer. Antiproliferative activity of ritonavir can also be mediated via inhibition of nuclear factor $\kappa \mathrm{B}(\mathrm{NF} \kappa \mathrm{B})$ translocation and transcriptional activation [25-26]. Recently we have shown that ritonavir can block hypoxiainduced angiogenesis through inhibition of HIF-1 $\alpha$ and VEGF [19]. Our study also indicated that ritonavir blocks HIF-1a-mediated protein translation in retinal pigment epithelial cells via inhibition of Akt phosphorylation.

Cell migration is another important cellular process involved in angiogenesis, wound healing and immune responses. Migration assay was performed to better correlate in vitro migratory potential 
A

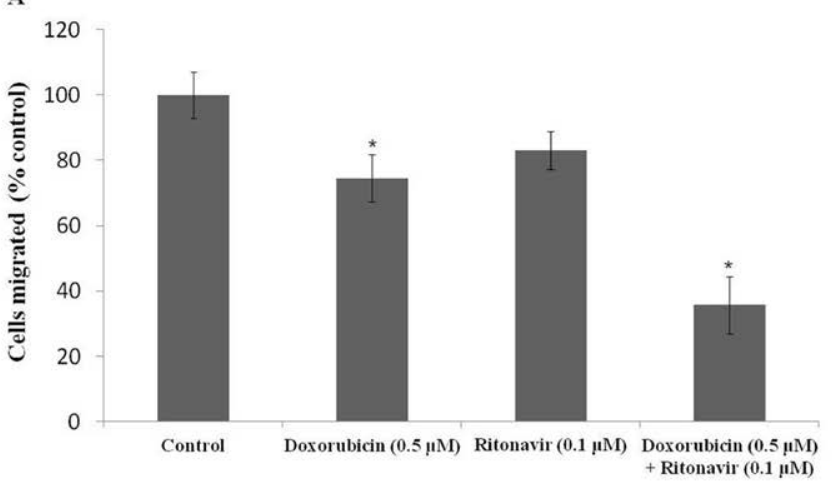

C

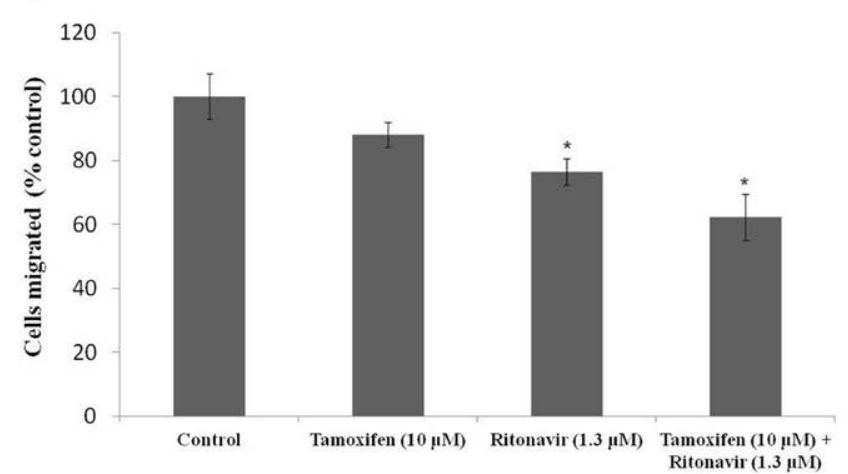

B

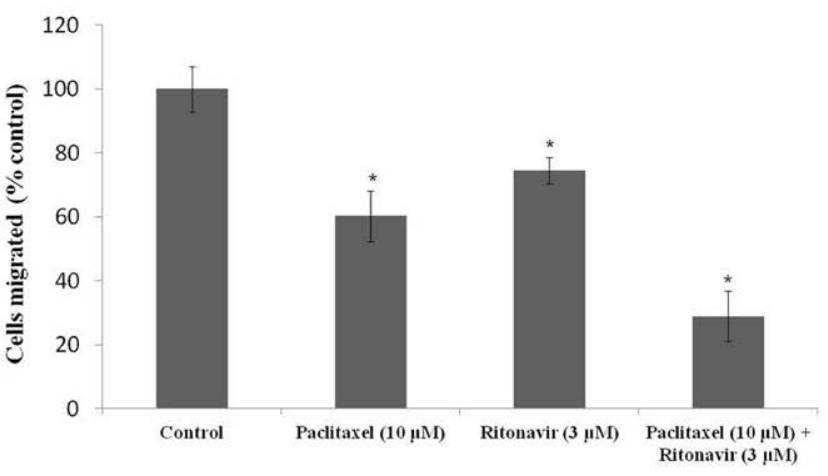

D

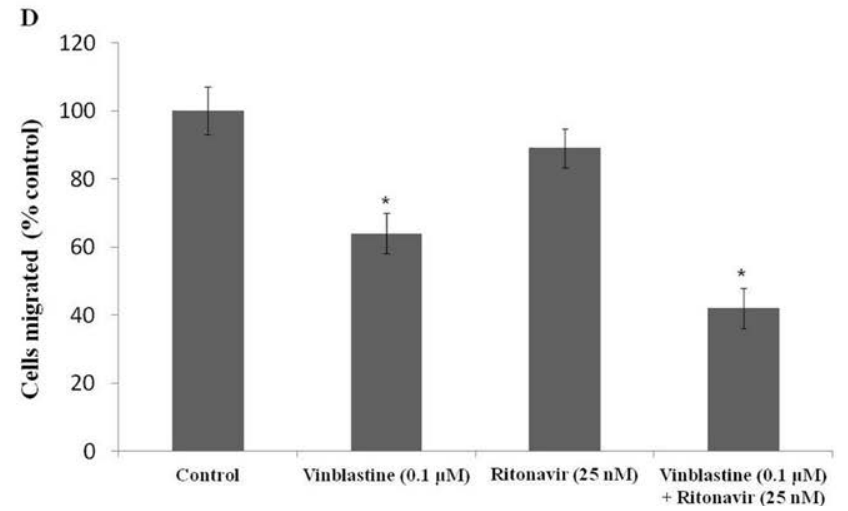

Figure 5: Relative number of T47D cells migrated towards $10 \%$ serum media post treatment with chemotherapeutic drug alone and in the presence of optimized concentration of ritonavir. Values represent mean percentage of cells migrated $\pm S D(n=6)$. A P-value of less than 0.05 was considered to be statistically significant and represented by *.

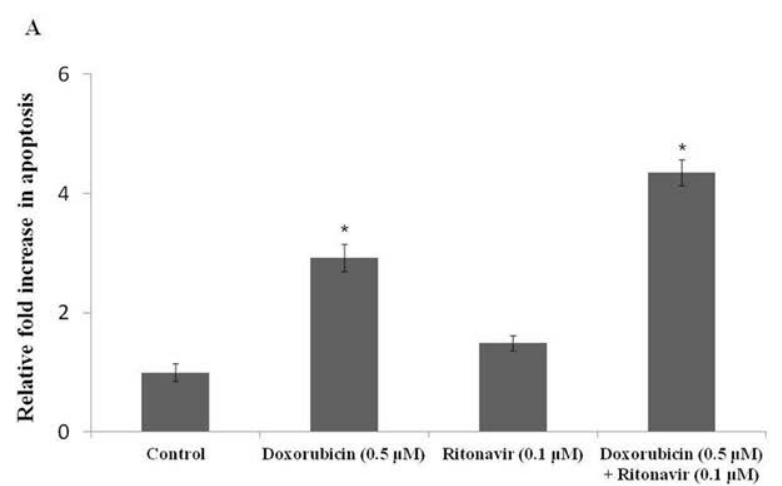

C

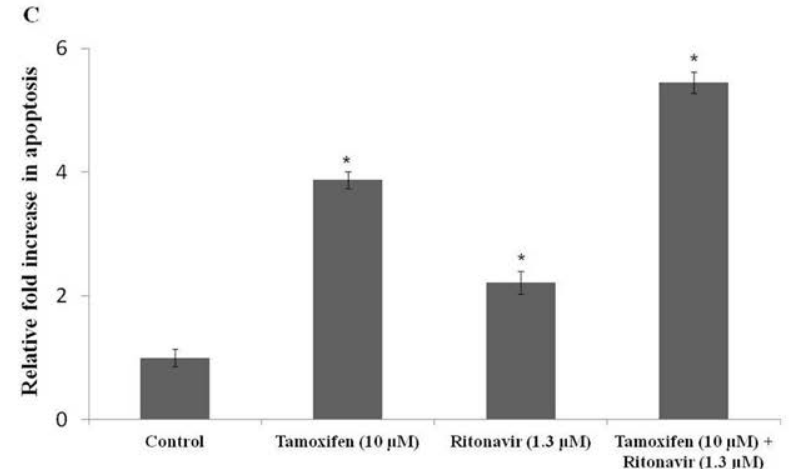

B

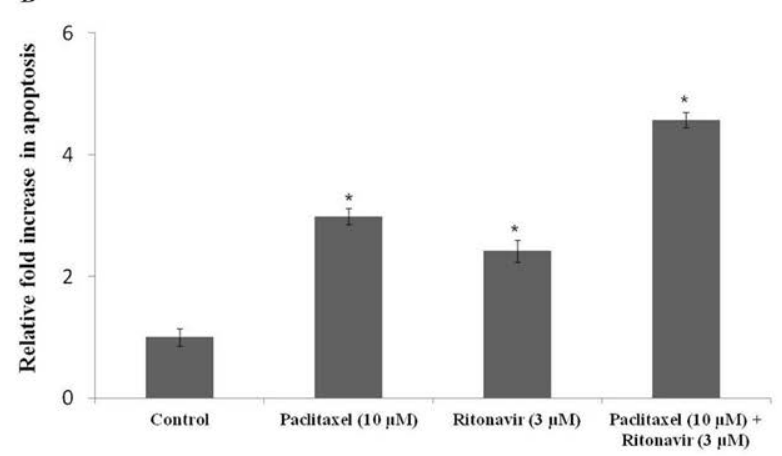

D

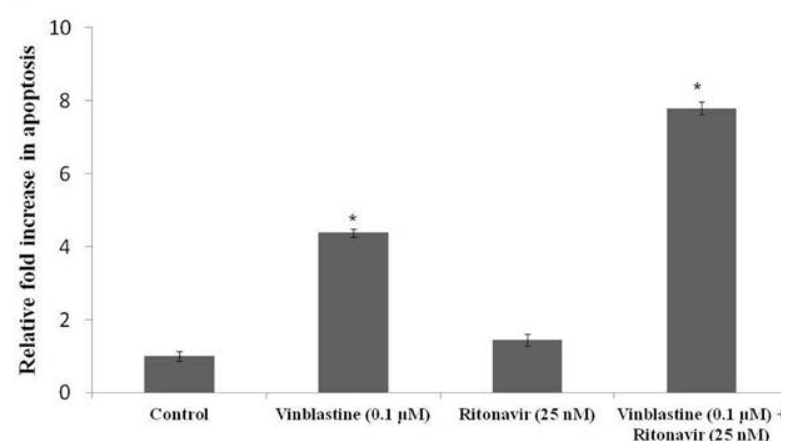

Figure 6: Relative levels of apoptosis inT47D cells post treatment with chemotherapeutic drugs alone and in the presence of optimized concentration of ritonavir. Values represent mean $\pm S D(n=6)$. A P-value of less than 0.05 was considered to be statistically significant and represented by *. 
of cancer cells to their in vivo invasive properties [27]. This assay was performed to better understand tissue repair and regeneration during cancer progression. All the four drugs, except for tamoxifen, inhibited cell migration significantly compared to control. Interestingly, cell migration was arrested by $30 \%$ in the presence of ritonavir and tamoxifen (Figure 5A-5D). Thus, both cell proliferation and migration assays further confirm potentiating activity of chemotherapeutics in combination with ritonavir.

Apoptosis is a process of programmed cell death that occurs to maintain development, homeostasis or aging [28]. A cascade of events involving multiple genes and proteins participate during apoptosis. Before the actual process of cell death proceeds by enzymes, specific signals trigger regulatory proteins to initiate apoptosis pathway. Several proteins participate in this cascade of events. Mitochondrial proteins, SMACs (small mitochondria-derived activator of caspase) deactivate SMAC binding to IAPs (inhibitor apoptosis proteins) permitting apoptosis to advance. Normally IAPs suppress the activity of cystine protease called caspases which execute final process of cell degradation. In our tests, we have observed a significant increase of caspase- 3/7 activities leading to cell death in response to all 4 anticancer agents (doxorubicin, paclitaxel, tamoxifen and vinblastine). The levels of apoptosis were further enhanced when ritonavir was combined with these anticancer agents (Figure 6A-6D). Relatively, ritonavir with vinblastine caused maximum apoptosis, almost seven fold enhancement of cell death compared to control. This significant increase in apoptotic cells may be due to enhanced cellular accumulation of anticancer agents in the presence of ritonavir promoting apoptosis. Role of ritonavir in this cascade is very complex. Ritonavir modulates proteasomal peptidase activity reversibly [29]. It inhibits chymotrypsin-like activity of isolated $20 \mathrm{~S}$ proteasomes allowing small amount of accumulation of tumor suppressor protein p53. Ritonavir has also been shown to accumulate a cyclin-dependent kinase inhibitor p21 (WAF-1), an indication of deregulation of cell-cycle progression leading to apoptosis through classical proteasomal inhibition [30]. Also, the expression of NF-kB-inducible protein p105 has been reported to be suppressed significantly by ritonavir [26]. Therefore, the inhibition of NF-kB activation by ritonavir may contribute to cellular apoptosis. Therefore, selective perturbation of proteasomal protein degradation along with inhibition of efflux transporter and CYP3A4 by ritonavir can enhance anti-tumoral activity.

In summary, coadministration of ritonavir with chemotherapy agents can counter balance the overexpression of MDR associated gene expression and overcome drug resistance in cancer therapy. This promising data indicate that ritonavir is of potential interest for chemotherapy and can form the basis for further development of a clinically applicable oral formulation of vinblastine or any other anticancer drug combined with ritonavir. The process of traditional drug development takes longer time and expensive. Ritonavir is FDA approved for human use and currently indicated for HIV treatment. Therefore, its repositioning in cancer chemotherapy may provide an excellent platform to reverse and overcome drug resistance besides providing enhanced antitumor efficacy. With such characteristics, ritonavir is expected to gain fast translational effect in chemotherapy.

\section{Conflict of Interest}

The authors declare no conflict of interest.

\section{References}

1. Lage $H$ (2008) An overview of cancer multidrug resistance: a still unsolved problem. Cell Mol Life Sci 65: 3145-3167.
2. Ullah, MF (2008) Cancer multidrug resistance (MDR): a major impediment to effective chemotherapy. Asian Pac J Cancer Prev 9: 1-6.

3. Vadlapatla RK, Vadlapudi AD, Pal D, Mitra AK (2013) Mechanisms of drug resistance in cancer chemotherapy: coordinated role and regulation of efflux transporters and metabolizing enzymes. Curr Pharm Des 19: 7126-7140.

4. Lippert TH, Ruoff HJ, Volm M (2008) Intrinsic and acquired drug resistance in malignant tumors. The main reason for therapeutic failure. Arzneimittelforschung 58: 261-264

5. Gatti L, Zunino F (2005) Overview of tumor cell chemoresistance mechanisms Methods Mol Med 111: 127-148.

6. Meijerman I, Beijnen JH, Schellens JH (2008) Combined action and regulation of phase II enzymes and multidrug resistance proteins in multidrug resistance in cancer. Cancer Treat Rev 34: 505-520.

7. Borst $P$, Elferink RO (2002) Mammalian ABC transporters in health and disease. Annu Rev Biochem 71: 537-592.

8. Wu CP, Hsieh CH, Wu YS (2011) The emergence of drug transporter-mediated multidrug resistance to cancer chemotherapy. Mol Pharm 8: 1996-2011.

9. Bardenheuer W, Lehmberg K, Rattmann I, Brueckner A, Schneider A, et al. (2005) Resistance to cytarabine and gemcitabine and in vitro selection of transduced cells after retroviral expression of cytidine deaminase in human hematopoietic progenitor cells. Leukemia 19: 2281-2288.

10. Sampath D, Cortes J, Estrov Z, Du M, Shi Z, et al. (2006) Pharmacodynamics of cytarabine alone and in combination with 7-hydroxystaurosporine (UCN-01) in AML blasts in vitro and during a clinical trial. Blood 107: 2517-2524.

11. Zahreddine $\mathrm{H}$, Borden $\mathrm{KL}$ (2013) Mechanisms and insights into drug resistance in cancer. Front Pharmacol 4: 28.

12. Szakács G, Paterson JK, Ludwig JA, Booth-Genthe C, Gottesman MM (2006) Targeting multidrug resistance in cancer. Nat Rev Drug Discov 5: 219-234.

13. Ozben T (2006) Mechanisms and strategies to overcome multiple drug resistance in cancer. FEBS Lett 580: 2903-2909.

14. Vadlapatla RK, Patel M, Paturi DK, Pal D, Mitra AK (2014) Clinically relevant drug-drug interactions between antiretrovirals and antifungals. Expert Opin Drug Metab Toxicol 10: 561-580.

15. Rathbun RC, Rossi DR (2002) Low-dose ritonavir for protease inhibitor pharmacokinetic enhancement. Ann Pharmacother 36: 702-706.

16. Harmsen S, Meijerman I, Febus CL, Maas-Bakker RF, Beijnen JH, et al. (2010) PXR-mediated induction of P-glycoprotein by anticancer drugs in a human colon adenocarcinoma-derived cell line. Cancer Chemother Pharmacol 66 : 765-771.

17. Vadlapatla RK, Vadlapudi AD, Kwatra D, Pal D, Mitra AK (2011) Differentia effect of P-gp and MRP2 on cellular translocation of gemifloxacin. Int J Pharm 420: $26-33$.

18. Vadlapatla RK, Vadlapudi AD, Ponnaluri VK, Pal D, Mukherji M, et al. (2013) Molecular expression and functional activity of efflux and influx transporters in hypoxia induced retinal pigment epithelial cells. Int J Pharm 454: 444-452.

19. Vadlapatla RK, Vadlapudi AD, Pal D, Mukherji M, Mitra AK (2014) Ritonavi inhibits HIF-1 1 t-mediated VEGF expression in retinal pigment epithelial cells in vitro. Eye (Lond) 28: 93-101.

20. Agarwal S, Pal D, Mitra AK (2007) Both P-gp and MRP2 mediate transport of Lopinavir, a protease inhibitor. Int J Pharm 339: 139-147.

21. Riddick DS, Lee C, Ramji S, Chinje EC, Cowen RL, et al. (2005) Cance chemotherapy and drug metabolism. Drug Metab Dispos 33: 1083-1096.

22. Harmsen S, Meijerman I, Beijnen JH, Schellens JH (2009) Nuclear receptor mediated induction of cytochrome P450 3A4 by anticancer drugs: a key role for the pregnane $\mathrm{X}$ receptor. Cancer Chemother Pharmacol 64: 35-43.

23. Gupta A, Mugundu GM, Desai PB, Thummel KE, Unadkat JD (2008) Intestinal human colon adenocarcinoma cell line LS180 is an excellent model to study pregnane $X$ receptor, but not constitutive androstane receptor, mediated CYP3A4 and multidrug resistance transporter 1 induction: studies with antihuman immunodeficiency virus protease inhibitors. Drug Metab Dispos 36 1172-1180.

24. Srirangam A, Mitra R, Wang M, Gorski JC, Badve S, et al. (2006) Effects of HIV protease inhibitor ritonavir on Akt-regulated cell proliferation in breast cancer. Clin Cancer Res 12: 1883-1896. 
Citation: Vadlapatla RK, Pal D, Vadlapudi AD Mitra AK (2014) Ritonavir: A Powerful Boosting Agent for Overcoming Drug Resistance in Cancer Chemotherapy. J Cancer Sci Ther 6: 446-454. doi:10.4172/1948-5956.1000307

25. Pajonk F, Himmelsbach J, Riess K Sommer A, McBride BH (2002) The human immunodeficiency virus (HIV)-1 protease inhibitor saquinavir inhibits proteasome function and causes apoptosis and radiosensitization in non-HIVassociated human cancer cells. Cancer res 62: 5230-5235.

26. Pati S, Pelser CB, Dufraine J, Bryant JL, Reitz MS Jr, et al. (2002) Antitumorigenic effects of HIV protease inhibitor ritonavir: inhibition of Kaposi sarcoma. Blood 99: 3771-3779.

27. Klemke RL, Leng J, Molander R, Brooks PC, Vuori K, et al. (1998) CAS/Crk coupling serves as a "molecular switch" for induction of cell migration. J Cell Biol 140: 961-972.
28. Vaux DL, Strasser A (1996) The molecular biology of apoptosis. Proc Natl Acad Sci U S A 93: 2239-2244.

29. Schmidtke G, Holzhütter HG, Bogyo M, Kairies N, Groll M, et al. (1999) How an inhibitor of the HIV-I protease modulates proteasome activity. J Biol Chem 274: 35734-35740.

30. Gaedicke S, Firat-Geier E, Constantiniu O, Lucchiari-Hartz M, Freudenberg M et al. (2002) Antitumor effect of the human immunodeficiency virus protease inhibitor ritonavir: induction of tumor-cell apoptosis associated with perturbation of proteasomal proteolysis. Cancer res 62: 6901-6908. 